\title{
Morphological Traits and Phenolic Compounds in Tunisian Wild Populations and Cultivated Varieties of Portulaca oleracea L.
}

\author{
Dorra Sdouga ${ }^{1}$, Ferdinando Branca ${ }^{2, * \mathbb{C}}$, Souhir Kabtni ${ }^{1}{ }^{\mathbb{D}}$, Maria Concetta Di Bella ${ }^{2}$, \\ Neila Trifi-Farah ${ }^{1}$ and Sonia Marghali ${ }^{1}$ (D) \\ 1 Laboratory of Molecular Genetics Immunology and Biotechnology (LR99ES12), Faculty of Sciences of Tunis, \\ University of Tunis El Manar, Campus Universitaire, 2092 Tunis, Tunisia; sdouga20@gmail.com (D.S.); \\ souhir.kabtni@fst.utm.tn (S.K.); neila.trifi@fst.utm.tn (N.T.-F.); sonia.marghali@fst.utm.tn (S.M.) \\ 2 Department of Agriculture, Food and Environment (Di3A), University of Catania, Via Valdisavoia 5, \\ 95123 Catania, Italy; maria.dibella@unict.it \\ * Correspondence: fbranca@unict.it
}

Received: 25 May 2020; Accepted: 28 June 2020; Published: 1 July 2020

check for updates

\begin{abstract}
This study aims to evaluate the bio-morphological and biochemical variability of three Tunisian wild populations and one growing cultivar of purslane (Portulaca oleracea L.). The studied varieties should be easily distinguished by the color and the habitus of the plant as mentioned in literature, but the various analyses have shown a strong morphological heterogeneity within and among the wild and cultivated accessions as presented by the variance analysis test (ANOVA) and the PCA (Principal component analysis). We found high intrapopulation variability through the wild populations that make it hard to differentiate them only on the base of morphology. We analyzed the biochemical profile of those populations based on the analysis of freeze-dried samples of leaves and stems. We identified and quantified twelve different phenolic compounds by the HPLC-diode array detector (DAD) technique. Six phenolic acids and flavonoids were identified in the leaves and stems of the wild and cultivated populations. Sinapic acid and myricetin are the majors identified compounds through our samples. The results were significantly different in relation to the plant organs and to the geographic origin for most of the compounds. The obtained results highlighted the importance of Portulaca as a medicinal plant by showing its richness in phenols and flavonoids that have multi-medicinal effects besides their antioxidant power.
\end{abstract}

Keywords: landrace; plant habitus; polyphenols; flavonoids; carotenoids; vegetables

\section{Introduction}

The Mediterranean basin is very rich in wild edible species which have been used for food and medicinal purposes for humans throughout the centuries [1]. Many of these species can be found near coastal areas and usually grow under saline conditions while others can adapt in various harsh conditions including high salinity [2,3]. Portulaca oleracea L., commonly known as "Purslane" or Blibcha in Tunisia and North Africa, is an annual green herbaceous weed. It is also a medicinal plant native to the Mediterranean basin, widespread in temperate and tropical regions of the world [4]. The number of species belonging to the Portulaca genus is uncertain, but it is estimated to be over 100 [5,6], morphologically very variable [7]. Two botanical forms are recognized in Tunisia such as the spontaneous subspecies growing as an invasive weed in irrigated crops and in rural inhabited areas, P. oleracea subsp. oleracea (P. oleracea var. sylvestris DC.), and the cultivated subspecies P. oleracea subsp. sativa (Haw.) Celak., with a suberect habitus and ascending stems [8]. 
Purslane was mentioned as a medicinal and food source in Egyptian texts from the time of the pharaohs $[9,10]$. It comprises more nutritive values than other vegetables due to its $w-3$ fatty acid, $\alpha$-tocopherol, ascorbic acid, $\beta$-carotene and glutathione-rich shoot [11]. Pharmacological investigations have indicated that $P$. oleracea produces a wide range of effects such as anti-inflammatory [12], antibacterial [13], skeletal muscle relaxant [14], and wound-healing [15], reducing cancer progress in vitro [16]. The several biochemical compounds such as terpenoids [17], alkaloids [18], cerebroside [19], coumarins, and flavonoids [20] probably are biologically active and are associated with the mentioned multi-pharmacological effects. Extracts of this plant may also stimulate signaling in $\beta$-cells and can be used for diabetes prevention [21]. In addition, those extracts inhibited the acetylcholinesterase (ACHE) enzyme, which is a key target in Alzheimer's disease treatment [21]. According to these researchers, this activity may be due to the dopamine and norepinephrine compounds present in P. oleracea ethanolic extracts. Moreover, leaf and root extracts of purslane could find application in sustainable and organic agriculture, since they present high allelopathic potential with further use as growth regulators and natural herbicides [22].

Few studies have addressed exploring the North African and Mediterranean germplasm of this species even though it is supposed to be a native of those regions. Salah and Chemli (2004) [8] studied the phenotypic variability of several Tunisian populations of P. oleracea, considering many morphological characters and hypothesizing that the detected differences were due to better and more stable growth conditions of the cultivated plants. Furthermore, Sdouga et al. (2018) [23] analyzed the intra-morphological variability of the wild population of Tunis that showed a high variability that has been not confirmed by the molecular analysis using ribosomal and chloroplast DNA barcodes. Accordingly, this work aims to explore the biochemical profile of this plant related to the morphological variation among different Tunisian accessions of wild and cultivated plants in order to identify different chemotypes of interest for nutraceutical purposes.

\section{Material and Methods}

\subsection{Plant Morphological Characterization}

Three wild populations of Portulaca oleracea L. were collected in Tunis (PTU), in Seliena (PSL) north of Tunisia, and in Sfax (PSF) south of Tunisia. Those regions are characterized with an arid to subarid climate. A cultivated population from Mahdia region (PMA) was also included to compare it with the wild populations. The growing cycle started from May till the end of August under greenhouse shelter at the Faculty of Sciences of Tunis. The seeds were sown in cellular trays at the beginning of May, and the seedling were transplanted after three weeks in $18 \mathrm{~cm}$ diameter pots, utilizing as a substrate peat (Pindstrup plus LV10336, GHS, Tunisia) and sand (1:1 in volume) by randomized block experimental design by four replicates of 10 plants each. No fertilizer or nutritive solutions were used throughout the growing season. The plants were watered regularly with $200 \mathrm{~mL}$ of tap water two times per week. The temperature varied between $26^{\circ} \mathrm{C}$ and $35^{\circ} \mathrm{C}$ in the day (Figure S1); 110 individuals of adult plants (fruiting stage) were characterized for the different morphological traits (Table 1). For the biochemical analysis, we collected the leaf and stem samples at the end of the growing cycle, and then, they were freeze-dried.

\subsection{Determination of Total Phenols and Carotenoids}

Total phenol content (TPC) was determined according to the Folin-Ciocalteau method after extraction in $70 \%$ acetone [24]. The values are expressed as $\mathrm{mg}$ of gallic acid equivalents (GEA) $\mathrm{g}^{-1} \mathrm{dry}$ weight (DM). The Folin-Ciocalteu reagent was purchased from Sigma-Aldrich (St. Louis, MO, USA), and the carotenoid determination was analyzed according to the protocol of Mayefield et al. (1986) [25] using $0.5 \mathrm{~g}$ of freeze-dried samples. 
Table 1. Variance analysis of the different characters.

\begin{tabular}{|c|c|c|c|c|c|c|c|}
\hline Descriptors & Stem Length & $\begin{array}{l}\text { Number of } \\
\text { Branches }\end{array}$ & $\begin{array}{l}\text { Length of } \\
\text { Branches }\end{array}$ & Leaf Number & Leaf Length & Leaf Width & Fruit Number \\
\hline Units & $(\mathrm{cm})$ & (n) & $(\mathrm{cm})$ & (n) & $(\mathrm{cm})$ & $(\mathrm{cm})$ & (n) \\
\hline PSL & $20.629 \pm 0.981 \mathrm{a}$ & $10.141 \pm 0.889 b c$ & $9.327 \pm 0.521 \mathrm{ab}$ & $117.626 \pm 6.823 \mathrm{a}$ & $4.893 \pm 0.229 a$ & $2.095 \pm 0.118 b$ & $6.880 \pm 0.551 b$ \\
\hline PTU & $15.286 \pm 0.889 b$ & $12.854 \pm 0.805 \mathrm{a}$ & $10.245 \pm 0.472 \mathrm{a}$ & $93.54 \pm 6.182 b$ & $3.705 \pm 0.208 b$ & $1.523 \pm 0.107 \mathrm{c}$ & $7.683 \pm 0.499 \mathrm{ab}$ \\
\hline PSF & $17.638 \pm 1.236 \mathrm{ab}$ & $12.764 \pm 1.120 \mathrm{ab}$ & $7.820 \pm 0.657 \mathrm{bc}$ & $90.220 \pm 8.598 b$ & $3.116 \pm 0.289 b$ & $1.538 \pm 0.149 c$ & $9.155 \pm 0.695 a$ \\
\hline PMA & $15.784 \pm 1.164 \mathrm{~b}$ & $8.005 \pm 1.055 \mathrm{~cd}$ & $9.723 \pm 0.619 \mathrm{ab}$ & $77.038 \pm 8.104 \mathrm{~b}$ & $4.458 \pm 0.272 \mathrm{a}$ & $2.392 \pm 0.141 \mathrm{a}$ & $5.096 \pm 0.654 \mathrm{c}$ \\
\hline FC & $* *$ & * & ns & ** & ** & $* *$ & ** \\
\hline F.h & $* *$ & $* *$ & ns & $* *$ & $* *$ & $* *$ & $* *$ \\
\hline $\mathrm{P} \times \mathrm{C} \times \mathrm{h}$ & ** & *** & ns & $* *$ & $* *$ & *** & ** \\
\hline
\end{tabular}

F.P, the population factor; $\mathrm{FC}$, the stems color factor; F.h, the plant habitus factor; $\mathrm{P} \times \mathrm{C} \times \mathrm{h}$, the interaction of all factors; $\mathrm{ns}^{*}$, and ${ }^{* *}$ indicate that the $\mathrm{F}$ test is not significant or significant at $p<0.05$ and $p<0.01$, respectively. The Duncan test results (at $5 \%$ level) are presented by letters (a, b, c, and d). Populations with the same letters did not show significant variability.

\subsection{HPLC Analysis}

The polyphenol content was analyzed in accordance with Soengas et al. (2012) [26] with some modifications [27]. For the extraction, $60 \mathrm{mg}$ of lyophilized powder was dissolved in $1.5 \mathrm{ml}$ of a 1:1 $\mathrm{v} / \mathrm{v}$ mixture of methanol and $0.04 \mathrm{~N} \mathrm{HCl}$. The mixture was vortexed for $1 \mathrm{~min}$ and then incubated for $10 \mathrm{~min}$ in ultrasonic. The mixture was centrifuged at $4{ }^{\circ} \mathrm{C}(20,000 \mathrm{~g}$ for $5 \mathrm{~min})$; the supernatant was collected for HPLC injection and conserved in $-20^{\circ} \mathrm{C}$ [28]. The HPLC analysis was performed using a HPLC Agilent 1200 series system (Agilent, Santa Clara, California, USA) equipped with a diode array detector (DAD). The analytical column was a Lichrospher 100RP-18 $(240 \times 4 \mathrm{~mm}$ i.d., particle size $=5 \mu \mathrm{m})$. The mobile phase contained water/acetic acid $(90: 10, \mathrm{v} / \mathrm{v}, \mathrm{A})$ and acetonitrile/acetic acid (90:10, v/v, B). Chromatography was performed with $0.6 \mathrm{~mL} / \mathrm{min}$ flow rate and the following gradient program: $0-7 \min 1 \% \mathrm{~B}, 7-20 \mathrm{~min} 30 \% \mathrm{~B}, 20-28 \mathrm{~min} 50 \% \mathrm{~B}, 28-33 \mathrm{~min} 50 \% \mathrm{~B}, 33-38 \mathrm{~min} 1 \% \mathrm{~B}$, and $38-48 \min 1 \% \mathrm{~B}$. The injection volume of the sample was $30 \mu \mathrm{L}$. Polyphenols were detected by DAD with monitoring the absorbance at 280, 310, 325, 350, and $520 \mathrm{~nm}$. Hence, the characterization of each phenol compound was based on its characteristic absorption spectra. Each sample was analyzed in triplicate. We identified the compounds based on their standards retention time and spectra to generate the calibration curve. Fourteen standards have been selected, and only 12 compounds have been identified: gallic acid, chlorogenic acid, caffeic acid, sinapic acid, syringic acid, p-coumaric acids and rutin, myricetin, scopoletin, quercitin, kaempferol, and apigenin. Ferulic and rosmarinic acids were not found in our samples. The tested standards were selected basing on previous studies [29-32]. Quantification was based on the calibration curves of external standards by comparing each compound through the absorption spectra. Concentrations were expressed in micrograms per gram of dry weight. The different obtained results were presented with the means and standard deviation (SD) of triplicate experiments

\subsection{Statistical Analysis}

We determined the analytical curves for TPC and HPLC-DAD and quantified the corresponding compounds in all samples in order to estimate the contents in each sample. According to linear equations for each calibration curve of equivalence compounds, we established gallic acid (TPC) and standard (HPLC) contents. All studied biochemical compounds and characters were subject to diverse statistical analysis. Analysis of variance (ANOVA; at a significant level of $p<0.05$ ) procedure in Xlstat 2018 software (Addinsoft, Paris, France) was used with a completely randomized design coupled with multiple comparisons of means (Tukey Contrasts) to investigate the differences between different organ assays for the biochemical analysis (experimental factor $\mathrm{O}=$ organ), the plants habitus (experimental factor $h=$ habitus), and the stem color (experimental factor $C=$ color) for the morphological analysis to compare selected Portulaca oleracea populations (P). Duncan test was performed to compare the 
means. All determinations were done at least in triplicates, and all were averaged. The confidence limits used in this study were based on $95 \%(p<0.05)$. The differences between the means values were compared using the Duncan multiple range test (at 5\% level) (Table 1 in letters). We evaluated the association between morphological variables by the Pearson correlation method via the Xlstat software. In addition, we completed discriminative analysis, namely PCA (principal compound analysis) by $R$ software using Factor MineR package (R core team, Vienna, Austria).

\section{Results}

\subsection{Bio-Morphological Characterization}

The morphological variability of four populations of Portulaca oleracea L. wild (PTU, PSF, and PSL) and cultivar from Mahdia (PMA) was evaluated. We have recurred to the analyses of 9 quantitative and qualitative morphological traits. We had studied the morphological variability of 110 individuals. The ANOVA method was used to determine the effect of population, the plant habitus (orthotropic or plagiotropic), and color of the stems (green or red) on all the morphological traits. The basic difference between the cultivated and wild varieties is the stem form and color [8]. The results are represented in the Table 1. The ANOVA revealed statistically significant differences between the populations for all morphological traits except the length of the branches; this result reveals the high interpopulation variability for the different studied quantitative characters.

We compared the mean value of the Tukey (HSD) on the basis of the populations' geographic origin for the different studied traits, and the results show a significant difference among the populations as demonstrated by the ANOVA test. On this basis, the Duncan test subdivided our populations into 2 groups for the stem length, number of fruits, branches, and leaves. It subdivides them in 3 groups $\mathrm{A}$, $B$, and $C$ for number of branches leaf length and width. For the number of fruits and leaves, leaf width, and stem length, those populations are represented in distinctive groups. The obtained results show that the cultivar (PMA) is presented by medium high adult plant with a prostrate green stem of almost $15.5 \mathrm{~cm}$ of length and some branches with fewer and bigger leaves. Those characteristics make the cultivars more accessible to harvest. For the wild populations, the ANOVA and Duncan test revealed the great morphological polymorphism among those populations. For the stem length characteristic, we found that the PSL was in a distinctive group from the other populations, with a higher recorded length that reached a mean of $20.6 \mathrm{~cm}$ also for leaf length and number of leaves, while PSF was distinct with a higher number of fruits, smaller leaves, and more branches compared to the PTU population. In general, based on the obtained results, the wild population of Portulaca oleracea seems to be more diversified with plagiotropic red stems with a higher number of branches and smaller but more leaves.

In fact, the Pearson correlation had confirmed this profile, with a negative correlation between the leaf size and the stem length, leaf and fruit number, leaf size, and branch number (Table 2). We found also a positive correlation between the stem length and number of branches from one side and the branches and the number of fruits and leaves from another that are biologically justified. This finding confirmed the previous profile of our studied populations. The principal component analysis (PCA) (Figure 1) allowed the original variables to be condensed into a lower number of independent variables. All the quantitative and qualitative characteristics were selected to display the discriminative analysis of the PCA as presented in the factors map. The percentage of variability revealed that the first two PCs accounted for $50.73 \%$ of the whole variation observed in the dataset. The first axis explained $32.26 \%$ of the variability. The second axis explained $17.87 \%$ of the variability. The PCA profile does not show clear distinctive groups of population individuals. It is difficult to distinguish a group of one population even when most of the individuals of the wild populations are concentrated in the left side of the first dim of the PCA and symmetrical to the PMA and PTU individuals, this distribution is mainly related to plants habitus (plagiotropic for wild and orthotropic for cultivated) and the stems color (red for wild and green for cultivated). This result reveals the high intrapopulation variability and that the two varieties (wild and cultivated) cannot be distinguished only on the basis of the morphology. 
Table 2. Pearson correlation of the morphological parameters.

\begin{tabular}{cccccccc}
\hline & $\begin{array}{c}\text { Stem } \\
\text { Length }\end{array}$ & $\begin{array}{c}\text { Number of } \\
\text { Branches }\end{array}$ & $\begin{array}{c}\text { Branches } \\
\text { Length }\end{array}$ & $\begin{array}{c}\text { Leaf } \\
\text { Length }\end{array}$ & $\begin{array}{c}\text { Leaf } \\
\text { Width }\end{array}$ & $\begin{array}{c}\text { Number } \\
\text { of Fruit }\end{array}$ & $\begin{array}{c}\text { Number } \\
\text { of Leaf }\end{array}$ \\
\hline Stem length & 1 & & & & & & \\
Number of branches & 0.395 & 1 & & & & & \\
Length of branches & 0.108 & 0.266 & 1 & & & & \\
Leaf length & 0.253 & -0.062 & 0.062 & 1 & & 1 \\
Leaf width & 0.272 & -0.269 & 0.019 & 0.479 & 1 & \\
Number of fruits & 0.281 & 0.36 & 0.095 & -0.056 & -0.09 & 1 \\
Number of leaves & 0.177 & 0.215 & 0.112 & 0.029 & -0.061 & -0.027 & 1 \\
\hline
\end{tabular}

Significant at $p<0.05$.

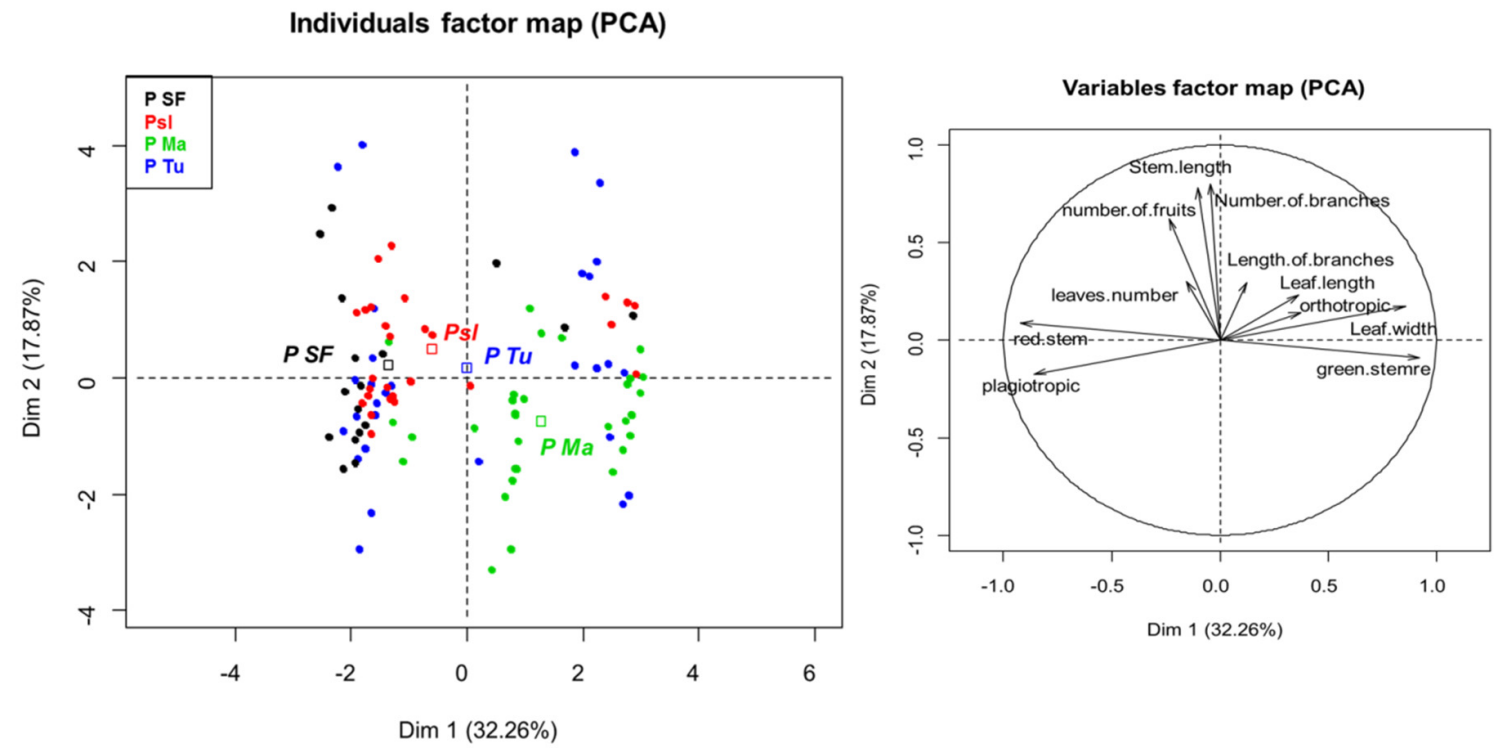

Figure 1. PCA of the morphological parameters (PMA: cultivars, PSL: wild population, PTU: wild population, and PSF: wild population).

\subsection{Biochemical Analysis of P. oleracea}

To study the biochemical composition of Portulaca oleracea accessions, we estimated the total polyphenol (TPC) and the carotenoid content for freeze-dried samples of the different wild and cultivated populations and their different parts. The obtained results showed more carotenoid compounds than the TPC with a mean of $3.2 \mathrm{mg} \cdot \mathrm{g}^{-1}$. For the TPC, the mean in the leaves is $1.7 \mathrm{mg} . \mathrm{g}^{-1}$ $\mathrm{DM}$ and the mean is $1.8 \mathrm{mg} \cdot \mathrm{g}^{-1} \mathrm{DM}$ in the stems. As presented in Table 3, the TPC was not significant for population or plant parts (Figure 1). For the carotenoids content, the Duncan result (presented by letters in the Table 3 and in Figure 2C) showed that the cultivated population PMA was in a distinct group. This is related to the fact that the cultivated variety is characterized by a green stem verse the wild one that are in red. We studied the composition in phenolic acids and flavonoids of P. oleracea (Figure 3). Fourteen standards have been selected, and only 12 compounds have been identified: gallic acid, chlorogenic acid, caffeic acid, sinapic acid, syringic acid, p-coumaric acids and rutin, myricetin, scopoletin, quercitin kaempferol, and apigenin. 
Table 3. ANOVA of Total phenol content (TPC) and carotenoids.

\begin{tabular}{|c|c|c|}
\hline Crop & $\begin{array}{l}\text { Carotenoids } \\
\left(\mathrm{mg} \cdot \mathrm{g}^{-1} \mathrm{DM}\right)\end{array}$ & $\begin{array}{c}\text { TPC } \\
\left(\mathrm{mg} \cdot \mathrm{g}^{-1} \mathrm{DM} \text { eq GEA }\right)\end{array}$ \\
\hline PSL & $3.467 \pm 0.229 a$ & $2.508 \pm 0.959 a$ \\
\hline PTU & $3.448 \pm 0.306 \mathrm{a}$ & $2.052 \pm 0.731 \mathrm{a}$ \\
\hline PMA & $2.240 \pm 0.295 b$ & $1.185 \pm 0.239 a$ \\
\hline PSF & $3.233 \pm 0.111 \mathrm{a}$ & $1.077 \pm 0.879 a$ \\
\hline mean & 3.097 & 1.706 \\
\hline F. P & $* *$ & ns \\
\hline F. $\mathrm{O}$ & $* *$ & ns \\
\hline $\mathrm{P} \times \mathrm{O}$ & $* *$ & ns \\
\hline
\end{tabular}

F.P., the population factor; F.O. the organs factor; $\mathrm{P} \times \mathrm{O}$, the interaction of the two factors; $\mathrm{ns}$ and ${ }^{* *}$ indicate that the $\mathrm{F}$ test is not significant or significant at $p<0.05$ and $p<0.01$, respectively. Letters indicate the DANCUN results (populations with the same letter didn't show significant variability).

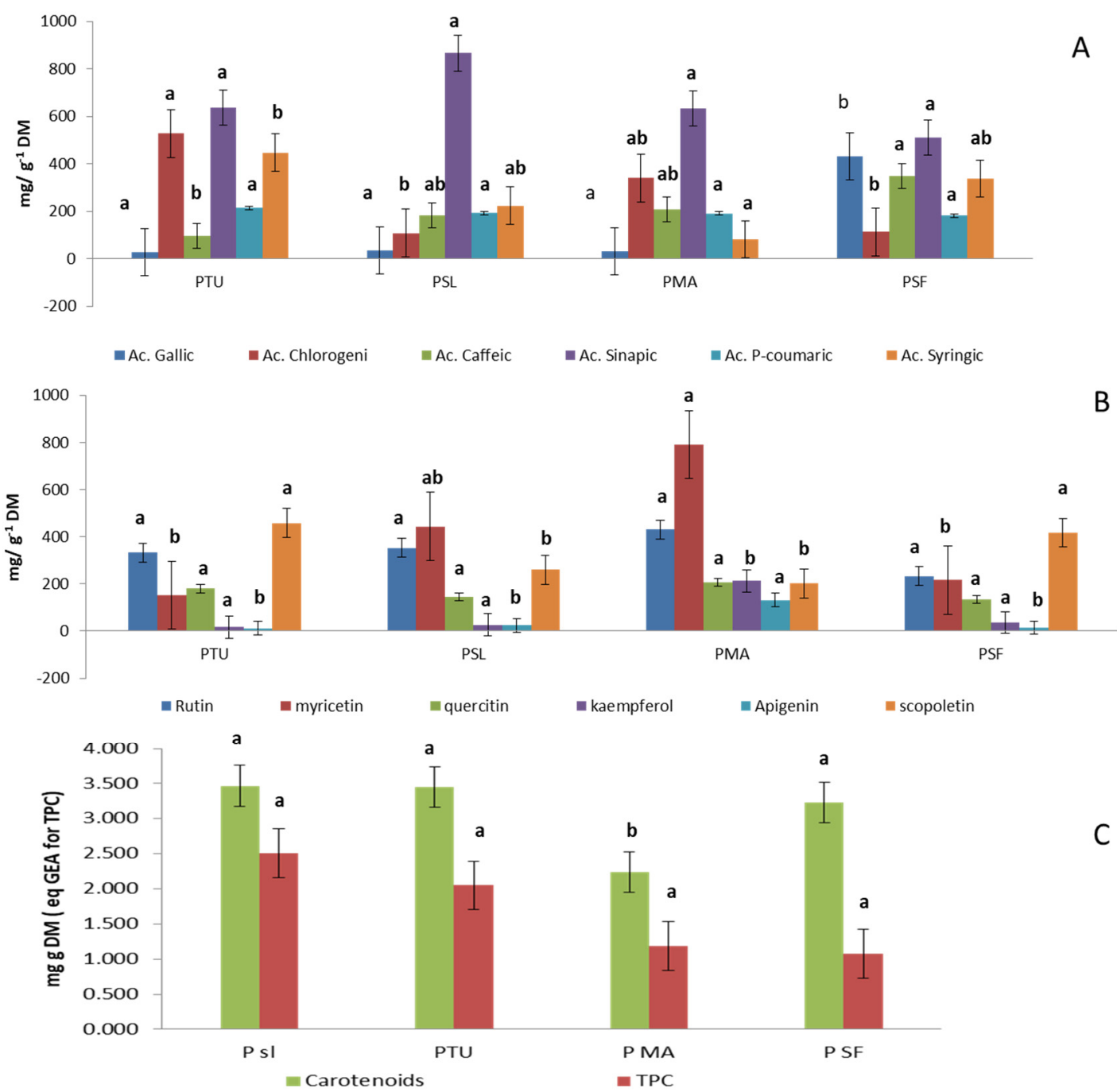

Figure 2. Mean comparison of the different phenolic compounds among populations by Duncan test (Populations with the same letter did not show significant variability for the studied character): (A) the profile of phenolic acids, (B) the profile of flavonoids, (C) TPC and carotenoid content (PMA: cultivars, PSL: wild population, PTU wild population, PSF wild population). 


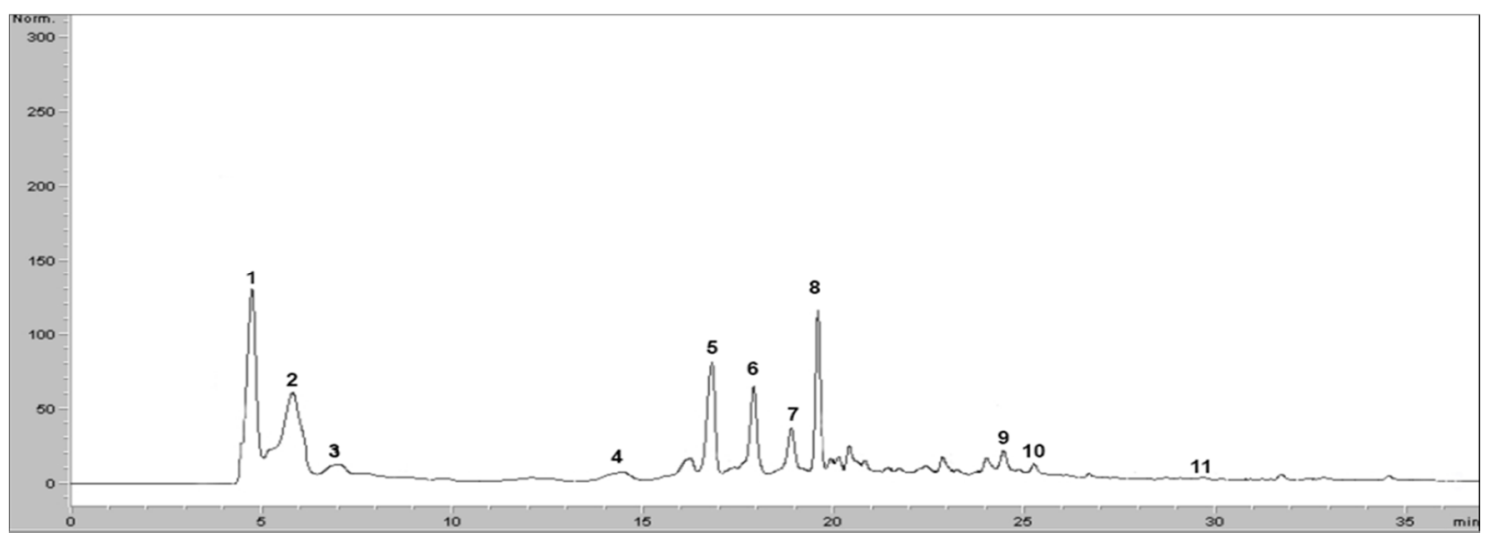

Figure 3. Chromatogram of the phenolic compounds identified in the leaves and stems of Portulaca. oleraceae (1, gallic acid; 2, chlorogenic acid; 3, caffeic acid; 4, sinapic acid; 5, syringic acid; 6, p-coumaric acid; 7 , rutin; 8 , myricetin; 9 , quercitin; 10 , kaempferol; and 11, apigenin).

The identified phenolic acids are listed in Table 4. The more abundant phenolic compound is sinapic acid in the leaves and the stems of the studied populations. The distribution of the phenolic compounds, separated in acidic phenols and flavonoids, was higher in the leaves. The multivariate analysis ANOVA revealed a significant variability of those compounds according to the geographic origin and to the plant organ for most of them as presented in Table 4 . The results revealed a significant distribution for all the phenolic acids according to the plant part. For the geographic origin of the studied plants, the results of ANOVA and Duncan (Figure 2) suggest a moderate effect of the population for the caffeic and syringic acids, while the variability was not significant for the sinapic and $p$-coumaric acids (Table 4).

For the flavonoids, five different compounds had been identified (Table 5). As for the phenolic acids, the leaves have a higher content in flavonoid and the myricetin as a major compound, and for the stems, rutin is the major compound. The ANOVA analysis is presented in the Table 5. As for the phenolic acids, the plant organ factor significantly influences all the identified flavonoids. For the population factor, it was significant only for myricetin and apigenin as confirmed by the Duncan test (Figure 2B).

The PCA analysis of the biochemical composition of Portulaca oleracea is presented in Figure 4. The first axis explained $39.71 \%$ of the variability. The second axis explained $23.73 \%$ of the variability. The different samples are grouped in 3 groups. The first group contains the PSL, PTU, PMA, and PSF populations and is symmetric to the second group by the first axis (Dim1) that groups the wild populations PTU and PSF. A third group is symmetric to the second group of PTU by the second axis (Dim 2) that contained the PMA population.

This result is in accordance with the Duncan test (Figure 2) and Tables 4 and 5; in fact, the cultivated population revealed higher content for myricetin, rutin, and Kaempferol (Figure 2B), and PTU and PSF had the higher content in scopoletin, synergic acid, and p coumaric acid (Tables 4 and 5). The first group (G1) is related to the TPC that did not show significative variability among the studied samples (Figure 2C and Table 2). 
Table 4. HPLC identified and quantified phenolic acids $\left(\mathrm{mg} / \mathrm{g}^{-1} \mathrm{DM}\right)$.

\begin{tabular}{cccccccccccccccc}
\hline Crop & \multicolumn{2}{c}{ Ac. Gallic } & \multicolumn{2}{c}{ Ac. Chlorogenic } & \multicolumn{2}{c}{ Ac. Caffeic } & \multicolumn{2}{c}{ Ac. Sinapic } \\
\hline \\
\hline
\end{tabular}

$\mathrm{P}=$ population factor; $\mathrm{O}=$ organs factor; $\mathrm{P} \times \mathrm{O}$, the interaction of the two factors; $\mathrm{ns}^{*}$, and ${ }^{* *}$ indicate that the $\mathrm{F}$ test is not significant or significant at $p<0.05$ and $p<0.01$ respectively.

Table 5. HPLC identified and quantified flavonoids $\left(\mathrm{mg} \mathrm{g}^{-1} \mathrm{DM}\right)$.

\begin{tabular}{|c|c|c|c|c|c|c|c|c|c|c|}
\hline & \multicolumn{2}{|c|}{ Rutin } & \multicolumn{2}{|c|}{ Myricetin } & \multicolumn{2}{|c|}{ Quercitin } & \multicolumn{2}{|c|}{ Kaempferol } & \multicolumn{2}{|c|}{ Apigenin } \\
\hline & Leaf & Stem & Leaf & Stem & Leaf & Stem & Leaf & Stem & Leaf & Stem \\
\hline PTU & $252.301 \pm 1.099$ & $410.966 \pm 8.724$ & $265.866 \pm 1.381$ & $38.366 \pm 3.672$ & $298.691 \pm 2.241$ & $59.711 \pm 2.069$ & $26.523 \pm 3.355$ & $7.933 \pm 2.095$ & $14.266 \pm 0.649$ & $10.233 \pm 0.975$ \\
\hline PSL & $475.433 \pm 3.729$ & $230.133 \pm 7.826$ & $782.766 \pm 4.307$ & $103.901 \pm 2.109$ & $243.602 \pm 2.003$ & $45.033 \pm 2.922$ & $46.233 \pm 1.547$ & $6.433 \pm 1.097$ & $34.933 \pm 3.451$ & $14.433 \pm 3.842$ \\
\hline PSF & $216.301 \pm 4.154$ & $250.233 \pm 7.926$ & $384.667 \pm 1.181$ & $47.166 \pm 1.150$ & $211.966 \pm 2.499$ & $56.466 \pm 01.971$ & $25.933 \pm 1.490$ & $46.211 \pm 1.411$ & $21.133 \pm 4.114$ & $7.266 \pm 0.327$ \\
\hline PMA & $798.333 \pm 2.639$ & $60.666 \pm 0.882$ & $1563.633 \pm 3.023$ & $16.366 \pm 3.667$ & $404.866 \pm 7.057$ & $6.922 \pm 1.30$ & $422.166 \pm 8.917$ & $2.633 \pm 0.252$ & $256.033 \pm 8.204$ & $6.266 \pm 0.504$ \\
\hline Mean & 435.592 & 237.992 & 749.233 & 51.455 & 289.783 & 42.025 & 130.211 & 15.725 & 81.592 & 9.556 \\
\hline F. P & \multicolumn{2}{|c|}{$* *$} & \multicolumn{2}{|c|}{ ns } & \multicolumn{2}{|c|}{ ns } & \multicolumn{2}{|c|}{ * } & \multicolumn{2}{|c|}{ ns } \\
\hline F. O & \multirow{2}{*}{\multicolumn{2}{|c|}{$\begin{array}{l}* * \\
*\end{array}$}} & \multirow{2}{*}{\multicolumn{2}{|c|}{$* *$}} & \multirow{2}{*}{\multicolumn{2}{|c|}{$* *$}} & \multirow{2}{*}{\multicolumn{2}{|c|}{$\begin{array}{l}* * \\
* *\end{array}$}} & \multirow{2}{*}{\multicolumn{2}{|c|}{$* *$}} \\
\hline $\mathrm{P} \times \mathrm{O}$ & & & & & & & & & & \\
\hline
\end{tabular}

$\mathrm{P}=$ population factor; $\mathrm{O}=$ organs factor; $\mathrm{P} \times \mathrm{O}$, the interaction of the two factors; $\mathrm{ns},{ }^{*}$, and ${ }^{* *}$ indicate that the $\mathrm{F}$ test is not significant or significant at $p<0.05$ and $p<0.01$, respectively. 


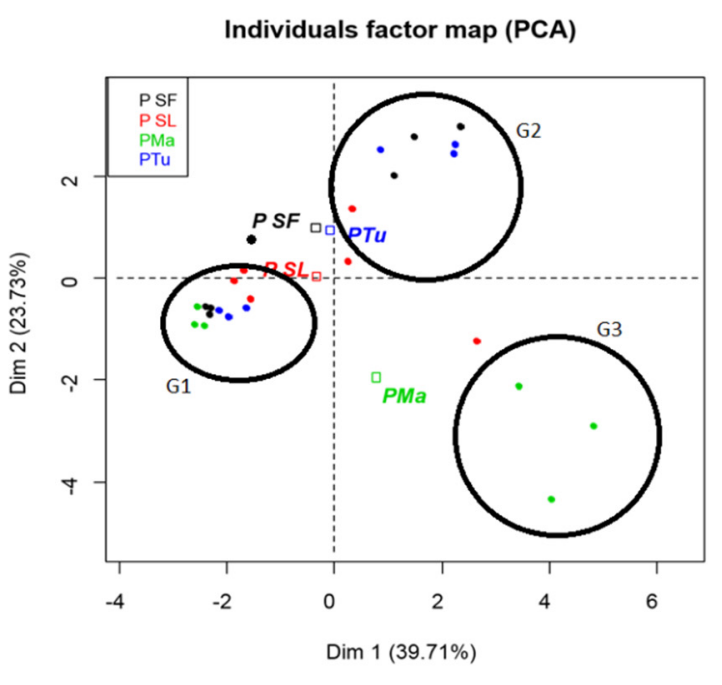

Variables factor map (PCA)

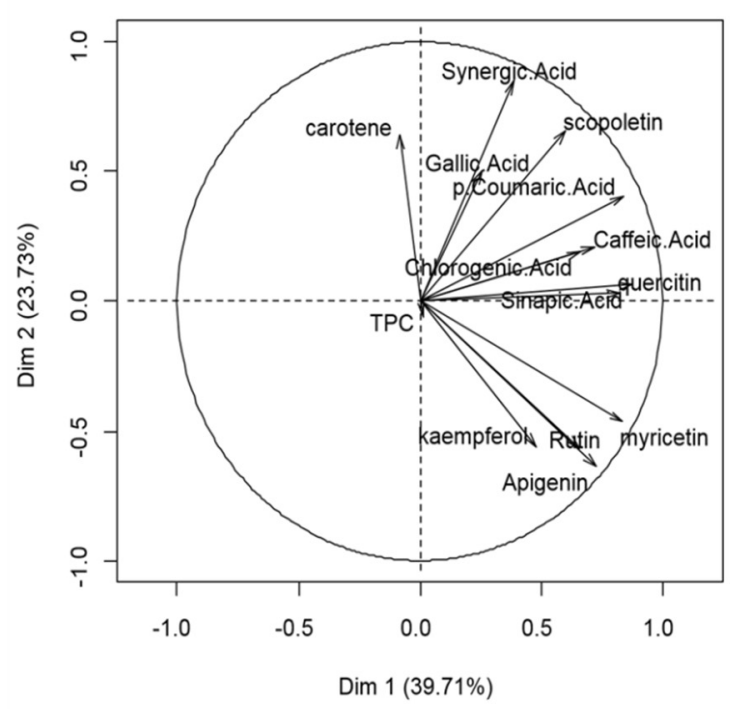

Figure 4. PCA of the biochemical compounds (PMA: cultivars, PSL: wild population, PTU: wild population, PSF wild population).

\section{Discussion}

\subsection{Bio-Morphological Characterization of the Wild and Cultivated Population}

The various statistical analyses performed for the studied characters have shown a strong interand intrapopulation heterogeneity for the wild and the cultivated population. In fact, our analysis focused on the two varieties: Portulaca oleracea subsp. sylvestris (DC.) Celak. and Portulaca oleracea subsp. sativa (Haw.) Celak., easily distinguished by the color of the stems and the plant habitus [33]. Our results showed high intrapopulation variability as confirmed by Salah and Chemli (2004) [8] and Sdouga et al. (2018) [23]. In fact, the ANOVA analysis with the Duncan test as presented in Table 1 showed a high variability within and among the populations and reflects the great morphological variability of this species. ANOVA values were mostly highly significant $(p<0.01)$ for most of the studied traits based on the population factor, the habitus, and the color of the stems except for the branches length that was not significant. This morphological variability have been explored in previous studied $[23,34]$ that showed high morphological plasticity of this species, and this could be explained by its genetic variability that revealed to be very complex $[35,36]$ and by the photosynthetic system in Portulaca genus [37]. This variability has contributed to its adaptability to abiotic stress conditions like salinity and drought $[3,38,39]$. Also, the large distribution area of this plant could contribute to this variability. The corresponding estimated average variation of traits (Duncan) was also significant for all characters mainly for leaves and the number of branches, where we can distinguish 3 groups. These findings show that the Tunisian populations (cultivars and wild) are genetically very close despite their geographical remoteness. The prostrate plants are characterized by a good vegetative vigor, with greater stem length, number of branches, and thicker leaves with a reddish coloration of the stem and branches. In self-pollinating species, the interpopulation morphological variability is correlated to the fluctuations of environmental conditions [40]. In fact, as we can see for the PCA of the morphological traits (Figure 1), it is not possible to distinguish clear groups for the wild and the cultivated populations, except for the two qualitative characteristics of green stems for cultivated population and plagiotropic habitus for the wild ones, but the group limits are not clear. The obtained results of our study are in accordance with Sdouga et al (2018) [23] and El-Bakatoushi et al. (2013) [34], who found that Portulaca oleracea is in fact very variable and polymorphic, especially morphologically, but that it is nondivisible in group or micro-species that are limited by a geographical distribution or 
morphological variability because it remains related to environmental conditions. To further investigate this diversity, we also studied the biochemical profile of wild and cultivated populations of Portulaca.

\subsection{Biochemical Composition of P. oleracea Accessions}

The biochemical composition of $P$. oleracea plants was explored and quantified by investigation of the total polyphenol content (TPC), the carotenoid content, and the composition in phenolic acids and flavonoids. Total phenol content has been reported to be associated with antioxidation activity in various plants [41]. The TPC for the different parts of the plant of the Tunisian populations of Portulaca oleracea were estimated, the obtained means are equivalent to $170 \mathrm{mg} / 100 \mathrm{~g}$ in the leaves, and the higher recorded content was for the wild population of Seliana PSL with a content of $428.4 \mathrm{mg} / 100 \mathrm{~g}$. In fact, the TPC depends on different factors, we cite the solvent and the method of extraction as explain Uddin et al. (2012) [42]. Organic solvent is more suitable for TPC extraction since they easily evaporate in water without forgetting the polyphenol oxidase that causes the oxidation of polyphenols. The results revealed the TPC in stems was slightly higher than the leaves. This result is not in accordance with those of Siriamornpun and Suttajit (2010) [31] on Thai purslane, where they found that the TPC content is higher in the leaf then in the stem and flower. In fact, according to Silva and Carvahlo (2014) [32], stems have a higher TPC and total antioxidant activity than leaves. Furthermore, we also investigated the carotenoid content in the different accessions for the leaves and stems. This compound has been reported to possess antioxidant activity because of its ability to neutralize free radicals and has the potential to prevent cardiovascular disease and cancer [43]. The carotene content in our samples is estimated at $3.159 \pm 0.633 \mathrm{mg} \cdot \mathrm{g}^{-1}$ in the leaves and $3.034 \pm 0.567 \mathrm{mg} \cdot \mathrm{g}^{-1}$ in the stems. Those means are almost 4 times higher than the Thai Portulaca [31]. In addition, Viana et al. (2015) [44], determined the total carotenoid content in purslane plants collected in Minas Gerais (Brazil) and observed that, from the total carotenoids content $\left(7.049 \mathrm{mg} .100 \mathrm{~g}^{-1}\right.$ dry mass), $0.105 \mathrm{mg} .100 \mathrm{~g}^{-1}$ was attributed to $\beta$ carotenoids. The Duncan analysis (Figure 2C) showed that the wild populations presented a higher significant content than in the cultivar PMA in which similar results were obtained by Alam et al. (2014) [45] who worked on different cultivars and wild populations of Portulaca.

HPLC-DAD is used for the quantification of the polyphenolic compounds and their identification. The compounds under study usually occur in plants as glycosides and methylated esters, or they may exist in their free form as well [46,47]. Phenolics range from simple, low molecular-weight, single aromatic-ringed compounds to large and complex tannins and derived polyphenols [47,48]. We identified 12 flavonoid and phenolic acids using the mix of 14 standards (Tables 4 and 5). Ferulic and rosmarinic acids were not found in our samples even though they have been identified in other collections of Portulaca $[31,32,42,45]$. It was possible to identify six phenolic acids: gallic, chlorogenic, sinapic, caffeic, syringic, and p-coumaric. The variability of the content in those phenols was significant in general between the populations according to their geographic origin but not to varieties. Those findings are in accordance with Alam et al. (2015) [45], whose results showed that the content of Portulaca oleracea in bioactive compounds is affected by the environmental conditions. The higher identified phenolic acids in our samples was the sinapic acid. This acid could not be identified in the Thai or Turkey accessions [29,31]. In fact, hydroxycinnamic acids are a kind of non-flavonoid phenolics characterized by the C6-C3 structure. These compounds are used in both structural and chemical plant defense strategies [46-49]. They can occur freely or as components of plant polymers, and they are presented in our samples by the p-coumaric and sinapic acids.

Flavonoids are involved in a vast array of biological functions and possess a wide range of pharmacological properties such as antibacterial, antivirus, anti-inflammation, and antioxidation properties. In the present study, we successfully quantified 6 flavonoids: rutin, myricetin, quercitin, kaempferol, and apigenin with a total mean of $225.886 \mathrm{mg} . \mathrm{g}^{-1} \mathrm{DM}$ through the different populations. Previous studies identified flavonoids of wild and cultivated Portulaca, and only two compounds, apigenin and kaempferol, were reported [30]. Also, the present results suggest a high variability within the different studied samples and those for the flavonoids and the phenolic acids, which suggest 
the strength relation between the geographic origin and environmental condition and the phenolic composition that will be interesting to investigate more through the Portulaca accessions. According to Zhu et al. (2010) [50], flavonoid levels vary according to the studied part of the plant; the highest levels are present in the root followed by stem and the leaf. In the present study, we found a higher content in the leaves over the stems as affirmed by the ANOVA analysis. Myricetin is the major compound in leaves, and rutin is the major compound in the stems. However, for the Thai purslane, rutin is the glycoside combining the flavone quercitin and the disaccharide rutinose found in leaves and myricetin in stems [31]. In the Italian accessions, quercetin was the major flavonoids in leaves [51]. This confirms the great variability of this plant and showed that the biochemical profile besides morphological characterization is related to the environmental condition. In the Tunisian P. oleracea plants, the quercetin level is estimated at $165.904 \mathrm{mg} \cdot \mathrm{g}^{-1} \mathrm{DM}$. This compound may aid in the prevention of certain diseases, such as cancer and chronic inflammation, by retarding oxidative degradation, by inducing enzymes that detoxify carcinogens, and by blocking the formation of cancer by deactivating at least 30 types of agents that may cause cancer [52,53]. In fact, quercetin and kaempferol as myricetin are flavanols which are the most widespread of the flavonoids [50,52,54]. Myricetin is a flavonoid that provides health benefits; in fact, it inhibits oxidation and cytotoxicity of low-density lipoproteins and may reduce the risk for heart disease or cancer [55-58]. It protects against two-stage skin tumor genesis and inhibits the growth of lung cancer cells. P. oleracea is one of the richest medicinal plants in this compound [59], and as we mentioned, it is a major compound in our samples. Also, the flavones apigenin extracted from this plant have showed a potential as an antibacterial, indicating that it can be used for the development of antibacterial drugs for the treatment of diseases associated with pathogenic bacteria. The different flavonoid and phenolic acids were found in the all plant parts (leaves and stem); leaves presented a higher amount of phenolic compounds than stems, which suggests that, in leaves, the synthesis of secondary metabolites is more developed than in stems, for which primary metabolism is more developed.

Also, the study of the biochemical composition of the wild and cultivated populations of Tunisia showed that both two varieties shared the same composition but with different amounts. The cultivated variety (PMA) is richer in flavonoids than the wild. As exposed in the Table 5 and the groups of the Duncan test (Figure 2B), for myricetin and apigenin, PMA is in distinct groups with higher amounts for those compounds. The wild populations presented higher contents in phenolic acids. In general, this study demonstrated a high variability through the southern Mediterranean studied accessions that have been presented by bio-morphological and biochemical vision. The different populations of purslane had significant bioactive compound content for the two varieties.

\section{Conclusions}

This study demonstrated the great morphological variability between and among the Tunisian populations and the cultivated variety of P. oleracea studied especially for the former ones. The main characteristics showing significant diversity among the genotype tested are the stem length; the number of branches; and the number, length, and width of the leaves. This morphological variability was also supported by the great biochemical diversity. The different organs of purslane showed significantly different bioactive compound content and revealed different levels of diversity in relation to both the geographic origin and the genotype. The different quantified compounds revealed a higher concentration in the leaves compared to the stems. The main polyphenol compounds are represented by myricetin and sinapic acid. The morphological and biochemical variability observed highlighted the potential of Portulaca oleracea species for its adaptability and for its great value as a medicinal plant.

Supplementary Materials: The following are available online at http://www.mdpi.com/2073-4395/10/7/948/s1, Figure S1: Variation of temperature $\left({ }^{\circ} \mathrm{C}\right)$ in the greenhouse.

Author Contributions: Conceptualization, F.B. and S.M.; data curation, D.S. and M.C.D.B.; formal analysis, M.C.D.B.; investigation, D.S. and N.T.-F.; methodology, F.B. and S.K.; project administration, S.M; resources, S.K.; software, D.S., S.K., and M.C.-D.B.; supervision, F.B. and S.M.; validation, F.B. and N.T.-F.; writing-original draft, 
D.S., F.B., and S.M.; writing—review and editing, F.B. All authors have read and agree to the published version of the manuscript.

Funding: This research received no external funding.

Acknowledgments: The authors are grateful to the "Ministère de l'Enseignement Supérieur" for the subvention (Bourse d'alternance-September 2016) and to the laboratory of Biotechnologies for Vegetable and Flower Crops of the Di3A, University of Catania, Italy.

Conflicts of Interest: The authors declare no conflict of interest.

\section{References}

1. Ceccanti, C.; Landi, M.; Benvenuti, S.; Pardossi, A.; Guidi, L. Mediterranean Wild Edible Plants: Weeds or "New Functional Crops"? Molecules 2018, 23, 2299. [CrossRef] [PubMed]

2. Petropoulos, S.A.; Karkanis, A.; Martins, N.; Ferreira, I.C.F.R. Edible halophytes of the Mediterranean basin: Potential candidates for novel food products. Trends Food Sci. Technol. 2018, 74, 69-84. [CrossRef]

3. Sdouga, D.; Ben Amor, F.; Ghribi, S.; Kabtni, S.; Tebini, M.; Branca, F.; Trifi-Farah, N.; Marghali, S. An insight from tolerance to salinity stress in halophyte Portulaca oleracea L.: Physio-morphological, biochemical and molecular responses. Ecotoxicol. Environ. Saf. 2019, 172, 45-52. [CrossRef] [PubMed]

4. Karkanis, A.C.; Petropoulos, S.A. Physiological and Growth Responses of Several Genotypes of Common Purslane (Portulaca oleracea L.) under Mediterranean Semi-arid Conditions. Not. Bot. Horti Agrobot. Cluj-Napoca 2017, 45, 569-575. [CrossRef]

5. von Poellnitz, K. Versuch einer Monographie der Gattung Portulaca L. Repert. Nov. Specierum Regni Veg. 1934, 37, 240-320. [CrossRef]

6. Ocampo, G.; Mair-Sánchez, L. Diversification of inflorescence types in Portulaca (Portulacaceae) and its systematic implications. Phytotaxa 2018, 358, 189. [CrossRef]

7. Geesink, R. An account of the genus Portulaca in Indo-Australia and the Pacific (Portulacaceae). Blumea Biodivers. Evol. Biogeogr. Plants 1969, 275-301.

8. Salah, K.B.H.; Chemli, R. Variabilité phénotypique de quelques populations de Pourpier (Portulaca oleracea L.) en Tunisie. Acta Bot. Gallica 2004, 151, 111-119. [CrossRef]

9. Kesden, D.; Will, A.A. Purslane: An ubiquitous garden weed with nutritional potential. Fla. State Hortic. Soc. Fla. State Hortic. Soc. 1987, 100, 195-197.

10. Mohamed, A.I.; Hussein, A.S. Chemical composition of purslane (Portulaca oleracea). Plant Foods Hum. Nutr. 1994, 45, 1-9. [CrossRef]

11. Wenzel, L.; Arvanitis, D.; Rabus, H.; Lederer, T.; Baberschke, K. Wenzel et al. reply. Phys. Rev. Lett. 1990, 65, 1522. [CrossRef] [PubMed]

12. Chan, K.; Islam, M.W.; Kamil, M.; Radhakrishnan, R.; Zakaria, M.N.M.; Habibullah, M.; Attas, A. The analgesic and anti-inflammatory effects of Portulaca oleracea L. subsp. sativa (Haw.). Celak. J. Ethnopharmacol. 2000, 73, 445-451. [CrossRef]

13. Kumar, B.S.A.; Prabhakarn, V.; Lakshman, K.; Nandeesh, R.; Subramanyam, P.; Khan, S.; Ranganayakalu, D.; Krishna, N.V. Pharmacognostical studies of Portulaca oleracea Linn. Rev. Bras. Farmacogn. 2008, 18, 527-531. [CrossRef]

14. Parry, O.; Marks, J.A.; Okwuasaba, F.K. The skeletal muscle relaxant action of Portulaca oleracea: Role of potassium ions. J. Ethnopharmacol. 1993, 40, 187-194. [CrossRef]

15. Rashed, A. Simple evaluation of the wound healing activity of a crude extract of Portulaca oleracea L. (growing in Jordan) in Mus musculus JVI-1. J. Ethnopharmacol. 2003, 88, 131-136. [CrossRef]

16. Yan, J.; Sun, L.-R.; Zhou, Z.-Y.; Chen, Y.-C.; Zhang, W.-M.; Dai, H.-F.; Tan, J.-W. Homoisoflavonoids from the medicinal plant Portulaca oleracea. Phytochemistry 2012, 80, 37-41. [CrossRef]

17. Xin, H.-L.; Xu, Y.-F.; Hou, Y.-H.; Zhang, Y.-N.; Yue, X.-Q.; Lu, J.-C.; Ling, C.-Q. Two Novel Triterpenoids from Portulaca oleracea L. Helv. Chim. Acta 2008, 91, 2075-2080. [CrossRef]

18. Yang, Z.; Liu, C.; Xiang, L.; Zheng, Y. Phenolic alkaloids as a new class of antioxidants in Portulaca oleracea. Phytother. Res. 2009, 23, 1032-1035. [CrossRef]

19. Xin, H.-L.; Hou, Y.-H.; Xu, Y.-F.; Yue, X.-Q.; Li, M.; Lu, J.-C.; Ling, C.-Q. Portulacerebroside A: New Cerebroside from Portulaca oleracea L. Chin. J. Nat. Med. 2008, 6, 401-403. [CrossRef] 
20. Xiang, L.; Xing, D.; Wang, W.; Wang, R.; Ding, Y.; Du, L. Alkaloids from Portulaca oleracea L. Phytochemistry 2005, 66, 2595-2601. [CrossRef]

21. Chen, Y.-X.; Li, G.-Z.; Zhang, B.; Xia, Z.-Y.; Zhang, M. Molecular evaluation of herbal compounds as potent inhibitors of acetylcholinesterase for the treatment of Alzheimer's disease. Mol. Med. Rep. 2016, 14, 446-452. [CrossRef] [PubMed]

22. El Shora, H.; Abd ElGawad, A. Evaluation of Allelopathic Effect of White Lupin (Lupinus termis L.) Leaf Extract on the Biochemical Dynamics of Common Purslane (Portulaca oleracea L.). Egypt. J. Bot. 2014, 54, 317-332. [CrossRef]

23. Sdouga, D.; Kabtni, S.; Hakim, L.; Branca, F.; Trifi-Farah, N.; Marghali, S. Integrated analysis for identifying Portulaca oleracea and its sub-species based on chloroplastic and nuclear DNA barcoding. Plant Biosyst. Int. J. Deal. Asp. Plant Biol. 2019, 153, 25-31. [CrossRef]

24. Singleton, V.L.; Orthofer, R.; Lamuela-Raventós, R.M. Analysis of total phenols and other oxidation substrates and antioxidants by means of folin-ciocalteu reagent. In Methods in Enzymology; Elsevier: Amsterdam, The Netherlands, 1999; Volume 299, pp. 152-178. ISBN 978-0-12-182200-2.

25. Mayfield, S.P.; Nelson, T.; Taylor, W.C. The Fate of Chloroplast Proteins during Photooxidation in Carotenoid-Deficient Maize Leaves. Plant Physiol. 1986, 82, 760-764. [CrossRef] [PubMed]

26. Soengas, P.; Cartea, M.E.; Francisco, M.; Sotelo, T.; Velasco, P. New insights into antioxidant activity of Brassica crops. Food Chem. 2012, 134, 725-733. [CrossRef]

27. Lo Scalzo, R.; Picchi, V.; Migliori, C.A.; Campanelli, G.; Leteo, F.; Ferrari, V.; Di Cesare, L.F. Variations in the Phytochemical Contents and Antioxidant Capacity of Organically and Conventionally Grown Italian Cauliflower (Brassica oleracea L. subsp. botrytis): Results from a Three-Year Field Study. J. Agric. Food Chem. 2013, 61, 10335-10344. [CrossRef]

28. Work, E. Chapter XIII Cell Walls. In Methods in Microbiology; Elsevier: Amsterdam, The Netherlands, 1971; Volume 5, pp. 361-418. ISBN 978-0-12-521505-3.

29. Erkan, N. Antioxidant activity and phenolic compounds of fractions from Portulaca oleracea L. Food Chem. 2012, 133, 775-781. [CrossRef]

30. Xu, X.; Yu, L.; Chen, G. Determination of flavonoids in Portulaca oleracea L. by capillary electrophoresis with electrochemical detection. J. Pharm. Biomed. Anal. 2006, 41, 493-499. [CrossRef]

31. Siriamornpun, S.; Suttajit, M. Microchemical Components and Antioxidant Activity of Different Morphological Parts of Thai Wild Purslane (Portulaca oleracea). Weed Sci. 2010, 58, 182-188. [CrossRef]

32. Silva, R.; Carvalho, I.S. In vitro antioxidant activity, phenolic compounds and protective effect against DNA damage provided by leaves, stems and flowers of Portulaca oleracea (Purslane). Nat. Prod. Commun. 2014, 9 , 45-50. [CrossRef]

33. Bosi, G.; Guarrera, P.; Rinaldi, R.; Mazzanti, M. Ethnobotany of purslane (Portulaca oleracea L.) in Italy and morphobiometric analyses of seeds from archaeological sites in the Emilia Romagna Region (Northern Italy). In Plants and Culture: Seeds of the Cultural Heritage of Europe; 2009; pp. 129-139. ISBN 978-88-7228-574-9.

34. El-Bakatoushi, R.; Alframawy, A.M.; Samer, M.; El-Sadek, L.; Botros, W. Evolution of the Portulaca oleracea L. aggregate in Egypt on molecular and phenotypic levels revealed by morphology, inter-simple sequence repeat (ISSR) and 18S rDNA gene sequence markers. Flora Morphol. Distrib. Funct. Ecol. Plants 2013, 208, 464-477. [CrossRef]

35. Ocampo, G.; Columbus, J.T. Molecular phylogenetics, historical biogeography, and chromosome number evolution of Portulaca (Portulacaceae). Mol. Phylogenet. Evol. 2012, 63, 97-112. [CrossRef] [PubMed]

36. Matthews, J.; Ketron, D.; Zane, S. The biology and taxonomy of the Portulaca oleracea L. (portulacaceae) complex in north america. Rhodora 1993, 95, 166-183.

37. Lara, M.V.; Drincovich, M.F.; Andreo, C.S. Induction of a Crassulacean Acid-like Metabolism in the C4 Succulent Plant, Portulaca oleracea L.: Study of Enzymes Involved in Carbon Fixation and Carbohydrate Metabolism. Plant Cell Physiol. 2003, 45, 618-626. [CrossRef] [PubMed]

38. Ren, S.; Weeda, S.N.; Akande, O.; Guo, Y.; Rutto, L.K.; Mebrahtu, T. Drought tolerance and AFLP-based genetic diversity in purslane (Portulaca oleracea L.). J. Biotech. Res. 2011, 3, 51-61.

39. Alam, M.; Juraimi, A.S.; Rafii, M.Y.; Abdul Hamid, A.; Aslani, F. Screening of Purslane (Portulaca oleracea L.) Accessions for High Salt Tolerance. Sci. World J. 2014, 2014, 1-12. [CrossRef]

40. Allard, R.W. Genetic Changes Associated with the Evolution of Adaptedness in Cultivated Plants and Their Wild Progenitors. J. Hered. 1988, 79, 225-238. [CrossRef] 
41. López-Vélez, M.; Martínez-Martínez, F.; Valle-Ribes, C.D. The Study of Phenolic Compounds as Natural Antioxidants in Wine. Crit. Rev. Food Sci. Nutr. 2003, 43, 233-244. [CrossRef]

42. Uddin, M.; Juraimi, A.S.; Ali, M.; Ismail, M.R. Evaluation of Antioxidant Properties and Mineral Composition of Purslane (Portulaca oleracea L.) at Different Growth Stages. Int. J. Mol. Sci. 2012, 13, 10257-10267. [CrossRef]

43. Rifici, V.A.; Khachadurian, A.K. Dietary supplementation with vitamins $C$ and $E$ inhibits in vitro oxidation of lipoproteins. J. Am. Coll. Nutr. 1993, 12, 631-637. [CrossRef]

44. Viana, M.M.; Carlos, L.A.; Silva, E.C.; Pereira, S.M.; Oliveira, D.B.; Assis, M.L. Phytochemical composition and antioxidant potential of unconventional vegetables. Hortic. Bras. 2015, 33, 504-509. [CrossRef]

45. Alam, M.; Juraimi, A.S.; Rafii, M.Y.; Abdul Hamid, A.; Aslani, F.; Hasan, M.M.; Mohd Zainudin, M.A.; Uddin, M. Evaluation of Antioxidant Compounds, Antioxidant Activities, and Mineral Composition of 13 Collected Purslane (Portulaca oleracea L.). Accessions. BioMed Res. Int. 2014, 2014, 1-10. [CrossRef] [PubMed]

46. Škerget, M.; Kotnik, P.; Hadolin, M.; Hraš, A.R.; Simonič, M.; Knez, Ž. Phenols, proanthocyanidins, flavones and flavonols in some plant materials and their antioxidant activities. Food Chem. 2005, 89, 191-198. [CrossRef]

47. Crozier, A.; Jaganath, I.B.; Clifford, M.N. Phenols, Polyphenols and Tannins: An Overview. In Plant Secondary Metabolites; Crozier, A., Clifford, M.N., Ashihara, H., Eds.; Blackwell Publishing Ltd.: Oxford, UK, 2006; pp. 1-24. ISBN 978-0-470-98855-8.

48. Pereira, D.; Valentão, P.; Pereira, J.; Andrade, P. Phenolics: From Chemistry to Biology. Molecules 2009, 14, 2202-2211. [CrossRef]

49. Oliveira, L.D.L.D.; Carvalho, M.V.D.; Melo, L. Health promoting and sensory properties of phenolic compounds in food. Rev. Ceres 2014, 61, 764-779. [CrossRef]

50. Zhu, H.; Wang, Y.; Liu, Y.; Xia, Y.; Tang, T. Analysis of Flavonoids in Portulaca oleracea L. by UV-Vis Spectrophotometry with Comparative Study on Different Extraction Technologies. Food Anal. Methods 2009, 3, 90-97. [CrossRef]

51. Gallo, M.; Conte, E.; Naviglio, D. Analysis and Comparison of the Antioxidant Component of Portulaca Oleracea Leaves Obtained by Different Solid-Liquid Extraction Techniques. Antioxidants 2017, 6, 64. [CrossRef]

52. Kim, J.-D.; Liu, L.; Guo, W.; Meydani, M. Chemical structure of flavonols in relation to modulation of angiogenesis and immune-endothelial cell adhesion. J. Nutr. Biochem. 2006, 17, 165-176. [CrossRef]

53. Ackland, M.L.; van de Waarsenburg, S.; Jones, R. Synergistic antiproliferative action of the flavonols quercetin and kaempferol in cultured human cancer cell lines. Vivo Athens Greece 2005, 19, 69-76.

54. Podsędek, A. Natural antioxidants and antioxidant capacity of Brassica vegetables: A review. LWT Food Sci. Technol. 2007, 40,1-11. [CrossRef]

55. Sicari, V.; Pellicanò, T.M.; Laganà, V.; Poiana, M. Use of orange by-products (dry peel) as an alternative gelling agent for marmalade production: Evaluation of antioxidant activity and inhibition of HMF formation during different storage temperature. J. Food Process. Preserv. 2018, 42, e13429. [CrossRef]

56. Fresco, P.; Borges, F.; Marques, M.; Diniz, C. The Anticancer Properties of Dietary Polyphenols and its Relation with Apoptosis. Curr. Pharm. Des. 2010, 16, 114-134. [CrossRef] [PubMed]

57. Hertog, M.G.L.; Feskens, E.J.M.; Kromhout, D.; Hertog, M.G.L.; Hollman, P.C.H.; Hertog, M.G.L.; Katan, M.B. Dietary antioxidant flavonoids and risk of coronary heart disease: The Zutphen Elderly Study. Lancet 1993, 342, 1007-1011. [CrossRef]

58. Batra, P.; Sharma, A.K. Anti-cancer potential of flavonoids: Recent trends and future perspectives. 3 Biotech. 2013, 3, 439-459. [CrossRef]

59. Ozcan, C.; Yaman, M. Determination of Myricetin in Medicinal Plants by High-Performance Liquid Chromatography. Instrum. Sci. Technol. 2015, 43, 44-52. [CrossRef]

(C) 2020 by the authors. Licensee MDPI, Basel, Switzerland. This article is an open access article distributed under the terms and conditions of the Creative Commons Attribution (CC BY) license (http://creativecommons.org/licenses/by/4.0/). 